\title{
An Evaluation of Student Learning Outcomes in Terms of Industry-Partnered Education
}

\author{
Oktay C. ADIGÜZEL*
}

\begin{abstract}
This study aims at evaluating student learning outcomes via student perceptions regarding the sixty-work day "Industry-Partnered Education (IPE)" given in engineering education programs. In the study, the survey method was employed, and the research data were collected through semi-structured interviews. As a consequence of the study, the process of industry-partnered education was found beneficial for students in the areas of business management, personal development and of institutional knowledge and applied skills. The study also revealed the sub-areas of learning outcomes related to each of these main areas of learning outcomes. Considering these learning outcomes revealed, the study discusses the university-industry partnership education programs and provides a perspective into how these partnership structures should be developed in order to improve engineering education.
\end{abstract}

Key Words: Industry-Partnered Education, Learning Outcome, Engineering Education, University-Industry Cooperation

\footnotetext{
*Assist.Prof., Anadolu University, Faculty of Education, ocadiguzel@anadolu.edu.tr, ocadiguzel@gmail.com
} 


\section{SUMMARY}

Purpose and Significance: Considering the rapid developments in today's technology, one of the areas where it is most possible to train qualified man-force includes engineering sciences. Parallel to these rapid developments in technology and in science, it is quite significant for engineering students to have the necessary knowledge and practical skills in their fields if they are to give reliable services of a good quality. In this respect, industry-partnered education programs to be developed by the university-industry cooperation are highly important in terms of engineering education. For this reason, evaluation of student learning outcomes in the present system plays an important role in observing the effectiveness of the industry-partnered education model, which is already applied in higher education. Based on the perceptions of students who go on their engineering education, the present study aims at evaluating the student learning outcomes in the process of industry-partnered education and tries to discuss the educational structures of university-industry partnership. The study seeks answers to the questions of "what are the student learning outcomes in the process of industry-partnered education?" and "What perspectives should be taken into consideration to structure the education programs of universityindustry partnership?" The student learning outcomes to be revealed in the scope of the study will shed light on the consequences of the industrypartnered education model and will provide insights into how industrypartnered education programs should be established.

Method: The study has the survey-model design and was carried out in the Faculty of Engineering and Architecture, Anadolu University. For the data collection procedure in the study, a qualitative research method was applied; thus, the research data were collected through semi-structured interviews. Participants included twenty-one prospective engineers (junior students at engineering education) attending the Faculty of Engineering and Architecture at one of the biggest universities in Turkey. Nine of them were female while twelve were male. On voluntary basis, three prospective engineers from each of the various programs (Computer Engineering, Environmental Engineering, Electrical and Electronics Engineering, Industrial Engineering, Civil Engineering, Chemical Engineering, and Materials Science and Engineering) were involved.

Results: It was revealed as a result of the analysis of the research data that the student learning outcomes in the process of industry-partnered education fall into three main areas: (1)The learning outcomes regarding the business world and business management were found to be in such four main areas as recognizing the operational structure of the business world and 
becoming aware of the difficulties; understanding the managerial and organizational structure of an enterprise; defining the formal relationships within an enterprise; and gaining a perspective into his or her future job. (2)The learning outcomes related to personnel development were found to occur in sub-areas like communication skills, industrial discipline, selfconfidence, patience and business struggle. (3)The learning outcomes concerning institutional knowledge and applied skills were found to fall into such main sub-areas as learning the practical use of their academic knowledge; learning the new systems, methods and techniques; and learning the new tools and equipment.

Conclusion: This study shows that industry-partnered education limited to 60 workdays isn't sufficient to acquire theoretical knowledge and practice skills. When learning outcomes of industry-partnered education is examined, it is concluded that, they are useful for students, largely, in getting an idea about industry world, obtaining general view about their professions and developing self-confidence. This limited role of industry on learning outcomes will have negative effects on Turkey's strength of competition, in multicultural, multilingual, and multinational world as a result of globalization. Consequently, in order to adapt to the developments in the world, that project-based educational programs be developed by establishing university- industry cooperation has become necessity. 


\title{
Sanayi Ortaklı Eğitim Kapsamında Öğrenci Kazanımlarının Değerlendirilmesi
}

\author{
Oktay C. ADIGÜZEL ${ }^{*}$
}

ÖZ. Bu çalışmada, mühendislik eğitim programları içerisinde altmış iş günü olarak yer alan "Sanayi Ortaklı Eğitim (SOE)" kapsamında oluşan öğrenci kazanımlarının, öğrenci görüşleri doğrultusunda değerlendirilmesi amaçlanmıştır. Çalışma, tarama türü bir araştırma olup, nitel araştırma yöntemlerinden, yarı-yapılandırılmış görüşmeler yoluyla gerçekleştirilmiştir. Çalışma sonucunda, sanayi ortaklı eğitim süresince öğrenci kazanımlarının; iş dünyasına ve işin yönetimine, kişisel gelişime, kuramsal bilgi ve uygulama becerisine ilişkin alanlarda gerçekleştiği tespit edilmiştir. Çalışmada tespit edilen her bir temel kazanım alanına ait oluşan alt kazanım alanları da belirlenmiştir. Çalışmada, tespit edilen bu kazanımlar doğrultusunda, üniversite-sanayi ortaklı eğitim programları tartışılarak, mühendislik eğitiminin geliştirilmesi kapsamında bu ortaklık yapılarının nasıl geliştirilmesi gerektiği konusunda bir perspektif sunulması amaçlanmıştır.

Anahtar Sözcükler: Sanayi Ortaklı Eğitim, Kazanım, Mühendislik Eğitimi, Üniversite Sanayi İşbirliği.

* Y.Doç.Dr., Anadolu Üniversitesi, Eğitim Fakültesi, Eğitim Programları ve Öğretim Ana Bilim Dal1, ocadiguzel@anadolu.edu.tr, ocadiguzel@gmail.com. 


\section{GíRIŞ}

Bilgi ve iletişim teknolojileri alanında yaşanan hızlı gelişmeler, bilgiye ulaşmanın ve bilgi paylaşımının kolaylaşması, ülke ekonomilerinin küreselleşmesine paralel olarak çok kültürlü, çok dilli, çok uluslu şirketlerin yaygınlaşması, toplumsal yaşamda ve iş alanlarında önemli dönüşümler meydana getirmektedir. Bir ülkenin, teknolojinin getirmiş olduğu bu dönüşümlere uyum sağlayarak gelişmiş ülkeler ile küresel dünya pazarında rekabet edebilmesi, daha güçlü bir ekonomi ve daha hılı bir toplumsal kalkınma gerçekleştirebilmesi için gerekli olan nitelikli insan gücüne sahip olabilmesi, bireylerine sunduğu eğitimin süresi ve niteliği ile bağlantılıdır.

Günümüz teknolojisinin ilerleme hızı dikkate alındığında, nitelikli insangücünün yetiştirilebileceği önemli alanlardan biri de mühendislik bilimleridir. Teknoloji ve bilimde yaşanan bu hızlı gelişmeler doğrultusunda, mühendislik eğitimi alan öğrencilerin, alanlarında gerekli bilgi ve becerilere sahip olmaları, yeterli uygulama deneyimi kazanmaları, verecekleri hizmetin niteliği ve güvenirliliği bakımından bir gerekliliktir. $\mathrm{Bu}$ doğrultuda, üniversite-sanayi arasında kurulacak olan sanayi ortaklı eğitim programları, mühendislik eğitiminde oldukça önem kazanmaktadır.

Üniversite ve sanayi arasında kurulan eğitim ortaklıklarında, kurumlar genellikle farklı amaçlar ile hareket edebilmektedirler. Üniversitelerin temel amacı öğretim iken sanayi kuruşlarının temel amacı ise üretim yapmaktır (Geay 1998). Bu iki sistem arasındaki öncelikli amaçların farklı olması, iş dünyası ve eğitim dünyası arasında zaman zaman uyuşmazlıkları ortaya çıkarabilmekte ve eğitim kurumları ile sanayi kuruluşları arasında kopukluklara yol açabilmektedir. Buna karşılık, nitelikli bir eğitim için, üniversiteler sadece kuramsal bilgilerin değil, aynı zamanda uygulamaya dönük becerilerin de kazanıldığı yerler; işletmeler ise, sadece uygulama becerisinin değil aynı zamanda kuramsal bilgilerinde öğrenildiği yerler olmalıdırlar (Pelpel, 2001). Dolayısıyla, mühendislik eğitiminde, sanayi ortaklığı ile oluşturulacak eğitim programlarının başarılı olabilmesi için, ortak eğitim modelinin, hem üniversitede hem de endüstride, bilgi ve becerilerin uyum içerisinde kazanılmasına olanak verecek bir yapı içerisinde olması oldukça önemlidir (Malglaive, 1996).

İşletmeler ile geliştirilen bu eğitim ortaklıklarında farklı uygulamalar olsa da, esas olarak iki farklı model bu ilişkileri yönlendirmektedir:

Birinci modelde, eğitim programı, okul-işletme ortaklığına dayanmakta, akademik ve endüstriyel eğitim, yıl içerisinde, işletme lehine artan oranlarda paylaştırılmaktadır. $\mathrm{Bu}$ eğitim programında işletmeler, mühendislik eğitiminde etkin bir paydaş olarak görev yapmaktadırlar. Genellikle, ileri 
derecede sanayileşmiş ülkelerde uygulanan bu model kapsamında, yükseköğretim kurumları, öğrencilerine, işletmeler ile ortak oluşturulan eğitim programları sunabilmekte ve öğrenciler, öğrenimlerinin önemli bir kısmını işletmelerde geçirebilmektedirler. Örnek olarak, Fransa'da birçok yükseköğretim kurumu, gerek ön lisans, gerekse lisans ve lisansüstü düzeylerde, işletmeler ile ortak eğitim programları geliştirmekte ve öğrenciler, daha önce protokol imzalanmış olan işletmeler ile ortaklaşa düzenlenen eğitime alınmaktadırlar. Benzer şekilde "Co-op Education" adıyla $\mathrm{ABD}$, Kanada, İngiltere ve Almanya gibi ileri sanayileşmiş ülke üniversitelerinde, ortak eğitim programları proje tabanlı olarak kendi sanayi ve kültürel özellikleri çerçevesinde gerçekleştirilmektedirler (Serbest \& Mandal 2006).

Ikinci modelde ise, eğitim programı, ağırlıklı olarak akademik eğitim yolu ile üniversiteler tarafından gerçekleştirilmektedir. Bu akademik eğitimin yanı sıra, programda, tatil dönemlerini kapsayan kısa süreli sanayi ortaklı eğitim yer almaktadır.

Türkiye'deki mevcut üniversite sisteminde, genel olarak, yukarıda bahsedilen ikinci modele giren, akademik eğitim ağırlıklı bir program uygulanmaktadır. $\mathrm{Bu}$ program kapsamında sanayi ile oluşturulan eğitim ortaklıkları öğrencilerin tatil dönemlerindeki süre içerisinde gerçekleştirilmektedir. Mühendislik eğitim programlarında "Staj" olarak yer alan ancak bizim "Sanayi Ortaklı Eğitim (SOE)" olarak adlandırdığımız bu zaman diliminde öğrenciler belirli dönemlerde sanayi kuruluşlarında, kuramsal bilgilerinin uygulama alanlarını keşfetmeye çalışmaktadırlar. Mühendislik fakültelerinde öğrenim gören öğrencilerin, mühendislik derecesini alabilmeleri için üniversitenin uygun gördüğü bu kuruluşlarda belirli konu, dönem ve sürelerde tamamlamaları öngörülen bu eğitim, mühendislik eğitim programlarında kredilendirilmemiş ancak mühendislik derecesinin alınabilmesi için zorunlu kılınmıştır. Sanayi ortaklı eğitimler; konu, uygulama ve değerlendirme açısından üniversiteden üniversiteye, bölümden bölüme farklılıklar göstermesine rağmen şartname, amaç ve yöntem bakımından birbirleri ile benzeşmektedirler (Kurban\&Şenel, 2006). Sanayi ortaklı eğitim, mevcut sistemde 4 yıllık eğitim süresi içerisinde 60 iş günü olarak belirlenmiş ve bu sürenin planlanması bölümlere bırakılmıştır. Eğitim yaz dönemlerinde veya dönem aralarında bir veya birden fazla kuruluşta gerçekleştirilebilmektedir. Sanayi ortaklı eğitim sonrasında öğrencilerden, işletmelerdeki günlük çalışmalarını içeren bir rapor hazırlayarak bölüm öğretim üyeleri tarafindan oluşturulan değerlendirme komisyonlarına teslim etmeleri istenmektedir. Bölümler isterlerse 
öğrencilerden sanayi'deki eğitimleri ile ilgili sunumlar da talep edebilmektedirler.

Tam zamanlı akademik eğitime dayanan bu eğitim programları, vakıf üniversitelerinin kurulması ile değișmeye başlamış, son zamanlarda üniversiteler ile işletmeler arasında ortak eğitim yapıları geliştirilmeye başlanmıştır. $\mathrm{Bu}$ bağlamda, mevcut sistemde öğrenci kazanımlarının değerlendirilmesi, yükseköğretimde halen uygulanan sanayi ortaklı eğitim modelinin etkililiğini gözlemlemekte oldukça önemlidir. Mühendislik eğitiminde üniversitelerin ve işverenlerin beklentilerine yönelik gerçekleştirilen çalışmalara karşın üniversite-sanayi eğitim ortaklığ sürecinin temel aktörleri olan öğrenciler üzerinde Türkiye'de yeteri kadar çalışma bulunmamaktadır. Bu çalışmada, mühendislik eğitimini sürdüren öğrencilerin görüşlerine dayalı olarak, sanayi ortaklı eğitim sürecinde oluşan öğrenci kazanımlarının değerlendirilmesi ve bu bağlamda, üniversite-sanayi ortak eğitim yapılarının tartışılması amaçlanmıştır. Bu bağlamda çalışma ile sanayi ortaklı eğitim sonucu oluşan öğrenci kazanımlarının neler olduğu ve üniversite-sanayi ortak eğitim programları hangi perspektifler doğrultusunda yapılandırılması gerektiği konu başlıklarına odaklanılmıştır.

\section{YÖNTEM}

\section{Katılımcilar}

Araştırma, Eskişehir Anadolu Üniversitesi, Mühendislik-Mimarlık Fakültesi üçüncü sınıf öğrencisi olan dokuzu bayan on ikisi erkek toplam yirmi bir öğrenci ile gerçekleştirilmiştir. Çalışmada Bilgisayar Mühendisliği, Çevre Mühendisliği, Elektrik Elektronik Mühendisliği, Endüstri Mühendisliği, İnşaat Mühendisliği, Kimya Mühendisliği, Malzeme Bilimi ve Mühendisliği olmak üzere her programdan gönüllülük esasına dayalı olarak üçer kişi belirlenmiş ve bu öğrenciler ile yarı yapılandırılmış görüşmeler gerçekleştirilmiştir.

Tablo 1. Katılımcilar

\begin{tabular}{lcc}
\hline \multicolumn{1}{c}{ Katılımcılar } & Katılımcı Kodları & KS* $^{*}$ \\
\hline İnşaat Mühendisliği & Kin & 3 \\
Elektrik ve Elektronik Mühendisliği & Kel & 3 \\
Malzeme Bilimleri ve Mühendisliği & Kma & 3 \\
Kimya Mühendisliği & Kki & 3 \\
Çevre Mühendisliği & Kçe & 3 \\
Endüstri Mühendisliği & Ken & 3 \\
Bilgisayar Mühendisliği & Kbi & 3 \\
\hline Toplam & & $\mathbf{2 1}$ \\
\hline KS*: Katılımcı sayıları
\end{tabular}

KS*: Katılımcı sayıları 


\section{Verilerin Toplanması ve Analizi}

Araştırmada veriler, nitel araştırma yöntemlerinden yarı yapılandırılmış görüşmeler yoluyla toplanmıştır. Yarı yapılandırılmış görüşmelerde, görüşme konularına ilişkin ana sorular önceden hazırlanmış, görüşme sırasında da, bu sorulara ilişkin yanıtları daha da belirginleştirmek ve ayrıntılı hale getirmek amacıyla açıklayıcı sorular yöneltilmiştir. Görüşmeler ortalama 20-25 dakika arası sürmüş ve tamamı dinleme cihazı ile kayıt altına alınmıştır. Görüşmelerde, öğrencilerin sanayi ortaklı eğitim sürecinde oluşturdukları kazanımları belirlemeye yönelik sorular yöneltilmiştir. Görüşme soruları Ek-A'da sunulmuştur. Betimsel analiz aşağıdaki işlemler gerçekleştirilerek yapılmıştır. (Yıldırım ve Şimşek, 2005; Blanchet ve Gotman, 2001):

1.Gerçekleştirilen tüm görüşmelerin, üzerinde hiçbir değişiklik yapılmadan görüşme formundaki sıraya göre dökümleri yapılmıştır.

2.Elde edilen verilerden yola çıkılarak tematik bir çerçeve oluşturulmuş, tespit edilen temalara kodlar verilmiştir.

3. Oluşturulan tematik çerçeve doğrultusunda, veriler okunarak, temaların frekansları çıkarılmıştır. Tespit edilen bu temalar ana başlıklar altında gruplandırılmışlardır. Belirlenen bu ana temalar altında alt temalar oluşturularak her bir öğrenci için frekans değerleri çıkarılmıştır. Oluşturulan tematik çerçevenin ve verilerin güvenilirliği için nitel araştırma ve alan bilgisine sahip iki uzmanın görüşüne başvurulmuştur.

4.Düzenlenen veriler tanımlanarak, bu veriler doğrudan alıntılarla desteklenmiştir. Böylece bulgular tanımlanmıştır ve yorumlanmıştır.

\section{BULGULAR}

Araştırma verilerinin analizleri sonucu sanayi ortaklı eğitim süresince, öğrenci kazanımlarının üç temel alanda oluştuğu tespit edilmiştir. Bu alanlar:

1. İş dünyasına ve işin yönetimine ilişkin kazanımlar(51\%);

2. Kişisel gelişime iliş̧in kazanımlar(32\%);

3. Kuramsal bilgi ve uygulama becerisine ilişkin kazanımlardır (17\%).

$\mathrm{Bu}$ alanlar doğrultusunda her birinin alt temaları belirlenerek, öğrenci kazanımları detaylandırılmışlardır. Tablo 2'de bu ana temaların frekans değerleri belirtilmiştir. 
Tablo 2. Öğrenci görüşleri doğrultusunda sanayi ortaklı eğitim sonucu oluşan kazanımların eğitim programlarına göre genel dağılımlar

*Öğrenci görüşlerinin alt kazanımlarına ilişkin frekans değerleri (Her öğrenci birden fazla kazanıma ilişkin görüş bildirebilmektedir).

\begin{tabular}{|c|c|c|c|c|c|c|c|c|}
\hline \multicolumn{2}{|c|}{ Katılımcilar } & \multicolumn{2}{|c|}{$\begin{array}{l}\text { Endüstriyel eğitim } \\
\text { süresince iş dünyasına } \\
\text { ve işin yönetimine } \\
\text { ilişkin kazanımlar }\end{array}$} & \multicolumn{2}{|c|}{$\begin{array}{l}\text { Endüstriyel eğitim } \\
\text { süresince kişisel } \\
\text { gelişime ilişkin } \\
\text { kazanımlar }\end{array}$} & \multicolumn{2}{|c|}{$\begin{array}{l}\text { Endüstriyel eğitim } \\
\text { sürecinde kuramsal } \\
\text { ve uygulama } \\
\text { becerisine ilişkin } \\
\text { kazanımlar }\end{array}$} & \multirow{2}{*}{$\begin{array}{c}\text { Toplam } \\
\\
\mathrm{f}\end{array}$} \\
\hline Kod & $S$ & $\mathrm{f}^{*}$ & $\%$ & $\mathrm{f}$ & $\%$ & $\mathrm{f}$ & $\%$ & \\
\hline Kin & 3 & 9 & 47 & 7 & 37 & 3 & 16 & 19 \\
\hline Kel & 3 & 7 & 46 & 4 & 27 & 4 & 27 & 15 \\
\hline $\mathrm{Kma}$ & 3 & 6 & 43 & 3 & 21 & 5 & 36 & 14 \\
\hline $\mathrm{Kki}$ & 3 & 8 & 47 & 6 & 35 & 3 & 18 & 17 \\
\hline Kçe & 3 & 8 & 54 & 5 & 33 & 2 & 13 & 15 \\
\hline Ken & 3 & 8 & 62 & 5 & 38 & - & - & 13 \\
\hline Kbi & 3 & 4 & 80 & 1 & 20 & - & - & 5 \\
\hline \multicolumn{2}{|c|}{ Toplam/21 } & 50 & 51 & 31 & 32 & 17 & 17 & 98 \\
\hline
\end{tabular}

Tablo 2'de belirtildiği gibi, sanayi ortaklı eğitim sürecinde tüm öğrencilerde en çok iş dünyasına ve işin yönetimine ilişkin kazanımların oluştuğu belirlenmiştir. Görüşlerine başvurulan öğrencilerden "Malzeme Bilimleri ve Mühendisliği”" bölümü öğrencileri haricinde diğer tüm öğrencilerde ikinci olarak kişisel gelişime ilişkin kazanımlarının oluştuğu ve üçüncü olarak da alanları doğrultusunda kuramsal bilgi ve uygulama becerileri edindikleri tespit edilmiştir.

\section{Sanayi ortaklı eğitim süresince iş dünyasına ve işin yönetimine iliş̧in kazanımlar}

Öğrenciler ile yapılan görüşmeler sonucu, sanayi ortaklı eğitim süresince öğrencilerin, en fazla kazanımlarının iş dünyasında ve işin yönetimine ilişkin gerçekleştiği tespit edilmiştir. $\mathrm{Bu}$ kazanımların: iş dünyasının işleyişini tanıma ve zorluklarını fark etme; işletme yönetim ve organizasyon yapısını anlama; işletme içi formal ilişkileri tanımlama; gelecekteki mesleğine ilişkin bakış açısı kazanma olarak dört temel alanda oluştuğu tespit edilmiştir. 
Tablo 3. Sanayi ortaklı eğitim süresince iş dünyasına ve işin yönetimine ilişkin kazanımlar

\begin{tabular}{ccc}
\hline $\begin{array}{l}\text { Sanayi ortaklı eğitim süresince iş dünyasına ve işin yönetimine iliş̧in } \\
\text { kazanımlar }\end{array}$ & f* & $\%$ \\
\hline a- İş dünyasının işleyişini tanıma ve zorluklarını fark etme & 18 & 36 \\
b- İşletme yönetim ve organizasyon yapısını anlama & 13 & 26 \\
c- İşletme içi formal ilişkileri tanımlama & 10 & 20 \\
d- Gelecekteki mesleğine ilişkin bakış açısı kazanma & 9 & 18 \\
\hline
\end{tabular}

Görüşmeler sonucunda, öğrenciler işletmelerde öncelikli olarak iş dünyasının işleyişi ve yaşanan zorluklar hakkında genel bir fikir edindiklerini belirtmişlerdir. Öğrenciler sanayi ortaklı eğitim süresince, işletmelerin yönetim ve organizasyon yapılarını tanıma firsatı bulduklarını ve işletme içerisindeki hiyerarşik yapılanmanın, işletme içerisindeki formal ilişkilerin nasıl yürütüldüğünü anladıklarını belirtmişlerdir. Öğrencilerin önemli bir kısmı, bu tecrübenin kendilerine gelecekteki mesleklerine ilişkin bir bakış açısı kazandırdığını ve ileride hangi koşullarda ve hangi alanlarda çalışabileceklerine ilişkin bilgi edinmelerine yardımcı olduğunu ifade etmişlerdir. Aşağıda üç öğrencinin bu konudaki görüşlerine yer verilmiştir:

Kin1: "Şantiye içerisindeki görevlerin neler olduğunu öğrendim. Kaba yapıdaki adamin görevi ile makine grubundaki adamin hangi derecelerde olduğunu bir şantiyede.... İş̧̧ileri, oradaki çalışan formen'ler olsun, iş̧te çaycısina kadar ne olduğunu ögrendim"

Kem1: "IŞs ortaminı gördüm.... Ortam nasıldır, nasıl yönetilir, müşterilere nastl davranılı ..... "

Kçe3: "Bir mühendisle teknisyen iş̧̧i arasındaki iletişimi görüyorsunuz. Oradaki ortamı gözlemliyorsunuz. Illeride işe girdiğiniz zaman nasıl davranmanız gerektiği konusunda biraz vizyon kazaniyorsunuz"

\section{Sanayi ortaklı eğitim süresince kişisel gelişime ilişkin kazanımlar}

Öğrenciler ile gerçekleştirilen görüşmeler sonucu, diğer kazanım alanlarının en çok kişisel gelişime ilişkin gerçekleştiği sonucuna varılmıştır. Kişisel gelişime ilişkin bu kazanımların: iletişim becerisi, iş disiplini, özgüven, sabır ve mücadelecilik alt alanlarında gerçekleştiği tespit edilmiştir. 
Tablo 4. Sanayi ortaklı eğitim süresince kişisel gelişime ilişkin kazanımlar

\begin{tabular}{ccc}
\hline Sanayi ortaklı eğitim süresince kişisel gelişime ilişkin kazanımlar & $\mathbf{f}$ & $\mathbf{\%}$ \\
\hline a- İletişim becerisi & 11 & 35 \\
b- Özgüven & 10 & 32 \\
c- İş disiplini & 7 & 23 \\
d- Sabır ve Mücadelecilik & 3 & 10 \\
\hline
\end{tabular}

Öğrenciler, işletmelerde geçirdikleri süre içerisinde, işletme çalışanları ile sosyal bir ilişki kurduklarını ve bu ilişkilerin, iletişim becerilerini geliştirdiğini ifade etmişlerdir.

Kişisel gelişime ilişkin diğer bir önemli kazanımında, öğrencilerin özgüven kazanımı olduğu yapılan görüşmeler sonucu tespit edilmiştir. Öğrenciler, işletmelerdeki eğitim öncesinde kendilerine yeterince güvenmedikleri, farklı bir ortam içerisinde kendilerini yeterince ifade edemediklerini ancak, işletmelerde geçirilen süreç sonrası kendilerine daha fazla güven geliştirdiklerini ve daha girişken olup kendilerini daha rahat ifade ettiklerini belirtmişlerdir.

Bu kazanımların yanı sıra, öğrencilerin bir bölümü, süreç sonrasında, işletmelerde etkin olarak çalışabilmek için girişken, sabırlı ve mücadeleci olmanın önemini kavradıklarını ve bu yönde beceriler geliştirdiklerini belirtmişlerdir. Aşağıda üç öğrencinin bu konudaki görüşlerine yer verilmiștir:

Kki1: "İlk başlarda ilk günlerde çok daha çekingen utanarak slkılarak giriyordum ama bu yıl başvuracağım stajlara çok daha rahat gidiyorum. Nasıl konuşacağımı ögrendim..."

Kma3: "İ̧ yaşamında çok sabırlı sakin soğukkanlı olmanın gerektiğini ve mücadeleci bir ruha sahip olunmasi gerektiğini anladım”

Kki2: "Ben şimdiye kadar bir genel müdürle oturup konuşamayacă̆ımı zannederdim ancak şimdi konuşabiliyorum."

\section{Sanayi ortaklı eğitim süresince kuramsal bilgi ve uygulama becerisine ilişkin kazanımlar}

Sanayi ortaklı eğitim süresince öğrenciler, meslek alanının keşfinin ve kişisel gelişim sağlamanın yanı sıra teknik alanda kuramsal bilgi ve uygulama becerisine ilişkin kazanımları da sağladıklarını ifade etmişlerdir. Öğrenciler ile yapılan görüşmeler sonucunda, bu kazanımların, akademik 
eğitimde öğrenilen bilgileri uygulamalı olarak görme; yeni sistem, yöntem ve teknikleri tanıma; yeni araç-gereçleri tanıma gibi temel alt alanlarda gerçekleştiği tespit edilmiştir.

Tablo 5. Sanayi ortaklı eğitim süresince kuramsal bilgi ve uygulama becerisine ilişkin kazanımlar

\begin{tabular}{ccc}
\hline $\begin{array}{l}\text { Sanayi ortaklı eğitim süresince kuramsal bilgi ve uygulama becerisine } \\
\text { ilişkin kazanımlar }\end{array}$ & $\mathrm{f}^{*}$ & $\%$ \\
\hline a- Akademik eğitimde öğrenilen bilgileri uygulamalı olarak görme & 8 & 47 \\
b- Yeni sistem, yöntem, teknikleri tanıma & 6 & 35 \\
c- Yeni araç-gereçleri tanıma & 3 & 18
\end{tabular}

Öğrenciler ile yapılan görüşmelerde, öğrencilerin üniversitedeki eğitimler sırasında öğrenmiş oldukları kuramsal bilgileri, işletmelerde uygulamalı olarak görme firsatı elde ettikleri tespit edilmiştir. Öğrencilerin bir kısmı, işletmelerde yeni hesap yöntemleri ve yeni teknikler öğrendiklerini ifade etmişlerdir. Bunların yanı sıra, öğrenciler işletmelerde, üniversite de görme veya kullanma imkânı bulamadıkları araç-gereçleri tanıdıkları ve nasıl kullanıldıkları konusunda bilgi sahibi olduklarını ifade etmişlerdir. Aşağıda üç öğrencinin bu konudaki görüşlerine yer verilmiştir:

Kki2: "Teknik anlamda genelde cihazları, akışlarını falan öğrendim. Yeni cihazlar tanıdım."

Kma1: "Kullanılan hammaddeleri isim olarak biliyordum. Ne özellikleri var ne katar cama onları biliyordum ama sonuçta bunu bir sonuç olarak görmek, mesela bir termallemenin nerelerde yapıldı̆̆ını görmek, bunları teorik olarak biliyordum uygulamada gördüm...."

Kma2: "Döküm yapılırken ufak kepçeler var elle dökümde. Orda kepçenin önemsiz olduğunu düşünüyordum ancak her şeyi önemliymiş. Boyutlart olsun, eğimi olsun her şeyi önemliymiş..."

\section{TARTIŞMA VE SONUÇ}

Türkiye, 70 milyonu aşan nüfusu ve sahip olduğu dünyanın 17. büyük ekonomik hacmi ile kendi bölgesinin en büyük ülkelerinden birisidir. Türkiye, gelecek on yılda daha güçlü bir ekonomiye sahip olmayı ve kişi başına düşen gayri safi milli hâsılayı artırmayı hedeflemektedir. Dolayısı ile gelişmekte olan Türkiye'nin, gelişen bilim ve teknolojiyi takip edebilmesi, küreselleşmenin getirmiş olduğu şartlara uyum sağlayabilmesi, daha güçlü bir ekonomi ve daha hızlı bir toplumsal kalkınma için gerekli olan nitelikli iş gücüne sahip olabilmesi için üniversitelerde verilen eğitimin niteliğini 
artıracak önlemleri alması oldukça önemlidir. $\mathrm{Bu}$ bağlamda mühendislik eğitiminin niteliğini yükseltmeye dönük yasal düzenlemeleri yapması ve bu eğitimin temel paydaşlarından biri olan iş dünyası ile ortak eğitim modellerinin geliștirilmesi bir gereklilik haline gelmiștir. Mevcut sistemde üniversiteler ile sanayi kuruluşları arasında test ölçüm hizmetleri, bilirkişi temini, bilimsel yayım temini, sorun analizi; mikro düzeyde insan-makina sistemlerinin iyileştirilmesi ve kalite ile ilgili sorunların çözümü gibi hizmet alımını kapsayan temel alanlarda ortak çalışmalar yürütülmektedir (Özok, 2006). Ancak görüldüğü üzere bu ortaklıklar ağırlıklı olarak hizmet alımı boyutunda gerçekleşmekte ve dolayısıyla sanayi'nin üniversitelerdeki eğitimin niteliğine dönük katkısı oldukça sınırlı kalmaktadır. Bununla beraber üniversitelerin mühendislik fakültelerinden diploma alan herkesin uygulama deneyimi ve birikimi olmaksızın mesleki yetki ile donatılması, hizmetin niteliği ve güvenirliliği bakımından uygulamada sakıncalar yaratmaktadır (Mekik\&Kuscu, 2006). Mevcut uygulamalara bakıldığ 1 zaman, yükseköğretim alanındaki yasal ve yapısal düzenlemelerinde böyle bir eğitim ortaklığına yeteri kadar imkân vermediği görülmektedir. Üniversite-sanayi arasındaki eğitim ortaklığı, dört yıllık bir mühendislik lisans eğitimi süresince, yalnızca 60 iş günü ile sınırlandırılmaktadır. $\mathrm{Bu}$ sınırlı sürenin verimli olmasına yönelik düzenlemelerinde oldukça yetersiz olduğu ve dolayısı ile mevcut sistemin birçok sorunu da bünyesinde barındırdığı yapılan çalışmalarda ortaya konmaktadır (Adıgüzel, 2007).

Gerçekleştirilen bu çalışma, 60 iş günü olarak sınırlandırılan sanayi ortaklı eğitimin, kuramsal bilgilerin ve uygulama becerilerinin edinilmesinde yeterli olmadığını göstermektedir. Sanayi ortaklı eğitimin sağladığı genel kazanımlar incelendiği zaman, ağırlıklı olarak, öğrencilerin iş dünyası hakkında bir fikir sahibi olmalarında, öğrencilerin gelecekteki mesleklerine ilişkin genel bir bakış açısı edinmelerini sağlamada ve bir özgüven geliştirmelerinde faydalı olduğu sonucuna varılmaktadır. Sanayi'nin öğrenci kazanımları üzerindeki bu sınırlı rolü, küreselleşme karşısında oluşan çok kültürlü, çok dilli, çok uluslu dünya pazarında, Türkiye'nin rekabet gücünü de olumsuz olarak etkileyebilecektir. Bu nedenle Türkiye'de üniversitesanayi işbirliğince oluşturulacak eğitim programlarının desteklenmesi, günümüz dünyasındaki gelişimlere uyum sağlanabilmesi için artık bir zorunluluk haline gelmiştir.

Sanayi ortaklı eğitimin, öğrenim görülen alana ilişkin geniş kazanımları sağlayabilmesi için, işletmeler ile düzenlenecek ikili anlaşmalar doğrultusunda proje tabanlı olarak yeniden tasarlanması gerekmektedir. Öğrencilerin iş dünyasını tanımaları ve çalışacakları meslek alanları hakkında bilgi sahibi olabilmeleri için, öğrenim sürelerinin ilk üç senesinde, 
mevcut sistemde olduğu gibi ancak işlevsel bir koordinatörlük yapısı ile farklı işletmelerde belirli süreler eğitim almalarına olanak sağlanmalıdır. İş dünyasını tanıma ve özgüven kazanma amaçlı bu sürelerin tamamlanmasından sonra, öğrencilerin tercih edecekleri uzmanlık alanlarına ilişkin kuramsal bilgi ve uygulama becerilerinin kazanılması amacıyla, üniversite ve işletme ortaklığınca geliştirilecek projeler içerisinde görev almaları ve öğretim sürelerinin son yılını işletme ve üniversite arasında geçirmeleri sağlanmalıdır. Bu uygulama öğrencilere öğrenim gördükleri programın belirli alanlarında uzmanlaşma imkânı sunabileceği gibi, öğrenim süreleri sonunda işletmelerde uygulama bulabilecek somut bir çalışma gerçekleştirme imkânı da sağlayacaktır. $\mathrm{Bu}$ düzenleme, öğrencilerin işletmeler tarafindan istihdam edilmelerini kolaylaştırabileceği gibi öğrencilerin işletmeye olan adaptasyon sürelerini de daha kısaltabilecek, böylelikle devletin harcamış olduğu eğitim masraflarının da geri dönüşümünü hızlandırabilecektir.

\section{Araştırmanın Sınırlılığı}

Araştırma verilerinin aynı üniversiteden ve sınırlı sayıda öğrenci ile elde edilmesi çalışmanın önemli sınırlılıklarından birisini oluşturmaktadır. Ancak nitel bir çalışmada, görüşmelerde elde edilen verilerin niteliğinin daha önemli olduğu prensibinden hareket edilerek katılımcılar ile derinlemesine görüşmeler gerçekleştirilmiştir. 


\section{KAYNAKLAR}

Adıgüzel O.C (2007). "Mühendislik Eğitimi Stajlarına Yönelik Bir Değerlendirme" Ulusal Teknik Eğitim, Mühendislik ve Eğitim Bilimleri Genç Araştırmacılar Sempozyumu, Cilt 2, 752-755 Kocaeli.

Blanchet, A. \& Gotman, A. (2001). L'enquête et ses méthodes l'entretien, Nathan Université: Paris

Geay A. (1998). L'école de l'alternance, Paris: Editions Harmattan.

Kurban M. \& Şenel, M. (2006). Mühendislik eğitiminin sanayiye açılan penceresi: Staj. II. Ulusal Mühendislik Kongresi, 11-13 Mayıs, 289294, Zonguldak.

Malglaive, G.(1996). Apprentissage, une autre formation pour d'autres ingénieurs. Formation et emploi, 53, 85-99.

Mekik, Ç., Kuşçu, Ş. (2006). Gelişmiş ülkelerdeki mühendislik unvanları ve edinme koşulları. II. Ulusal Mühendislik Kongresi, 11-13 Mayıs, 239247, Zonguldak.

Özok A.F.(2006) Üniversite-Sanayi ilişkilerinin etkinleştirilmesi. II. Ulusal Mühendislik Kongresi, 11-13 May1s, 57-61, Zonguldak.

Pelpel P. (2001). Apprendre et faire. France: Harmattan.

Serbest, A.H. \& Mandal, H.(2006). Üniversite-Sanayi İşbirliğinin Geliștirilmesi için Eğitim Sistemi içinde uygulanabilecek öneriler Bildiri, II. Ulusal Mühendislik Kongresi 269-278, Zonguldak.

Yıldırım, A. \& Şimşek H. (2005). Sosyal Bilimlerde Nitel Araştırma Yöntemleri (5. Baskı), Ankara: Seçkin Yayıncılık. 


\section{EK A}

\section{YARI YAPILANDIRILMIŞ GÖRÜŞME SORULARI}

\section{Sanayi Ortaklı Eğitime İlişkin Genel Bilgiler}

- Sanayi ortaklı eğitim kapsamında öğrenim göreceğiniz işletmeyi nasıl belirlediniz?

- Öğrenim gördüğünüz işletmeyi kısaca tanıtır mısınız?

- İşletmede bulunduğunuz süre içerisinde hangi tür sorumlulukları üstlendiniz, örnek verebilir misiniz?

\section{Sanayi Ortaklı Eğitime İlişkin Kazanımlar}

- Sanayi ortaklı eğitimin size hangi temel kazanımları sağladığını düşünüyorsunuz?

- Sanayi ortaklı eğitim, üniversitedeki akademik eğitiminiz ile paralel olarak hangi kazanımları pekiştirmenizi sağladı?

- Sanayi ortaklı eğitim, üniversitede sürdürdügünüz akademik eğitimden farklı olarak hangi kazanımları elde etmenizi sağladı?

- Sanayi ortaklı eğitim süresince elde ettiğiniz hangi kazanımların, akademik eğitiminize olumlu katkısı olduğunu düşünüyorsunuz?

- Sanayi ortaklı eğitim öncesi beklentileriniz nelerdi? Bu süreç hangi beklentilerinize karşı1lı verdi?

- Sanayi ortaklı eğitim, öğrenim gördüğünüz meslek alanına ilişkin bakış açınızı nasıl etkiledi? 